\title{
AR\&Al in the Didactics of the Representation Disciplines
}

\author{
Roberta Spallone \\ Valerio Palma
}

\section{Abstract}

The class of Digital Representation Techniques is an optional class for architecture and engineering students at the Politecnico di Torino. For the second year, the program of the class, focused on the theoretical and applicative panorama of technologies for digital drawing, integrates an introduction to the most recent developments in augmented reality (AR) and artificial intelligence (AI), two technological fields that are deeply influencing the interpretation of physical assets through digital models. The class requires students to produce different deliverables, including a research essay, graphic representation documents (plates or brochures), a video proving animation and editing skills, and a prototype AR application. The proposed contribution presents methods, objectives, and some of the results of the class, highlighting the interaction between the different digital representation techniques and deepening the critical aspects related to the introduction of new AR and Al technologies.

Keywords

augmented reality, artificial intelligence, didactics, representation, design.

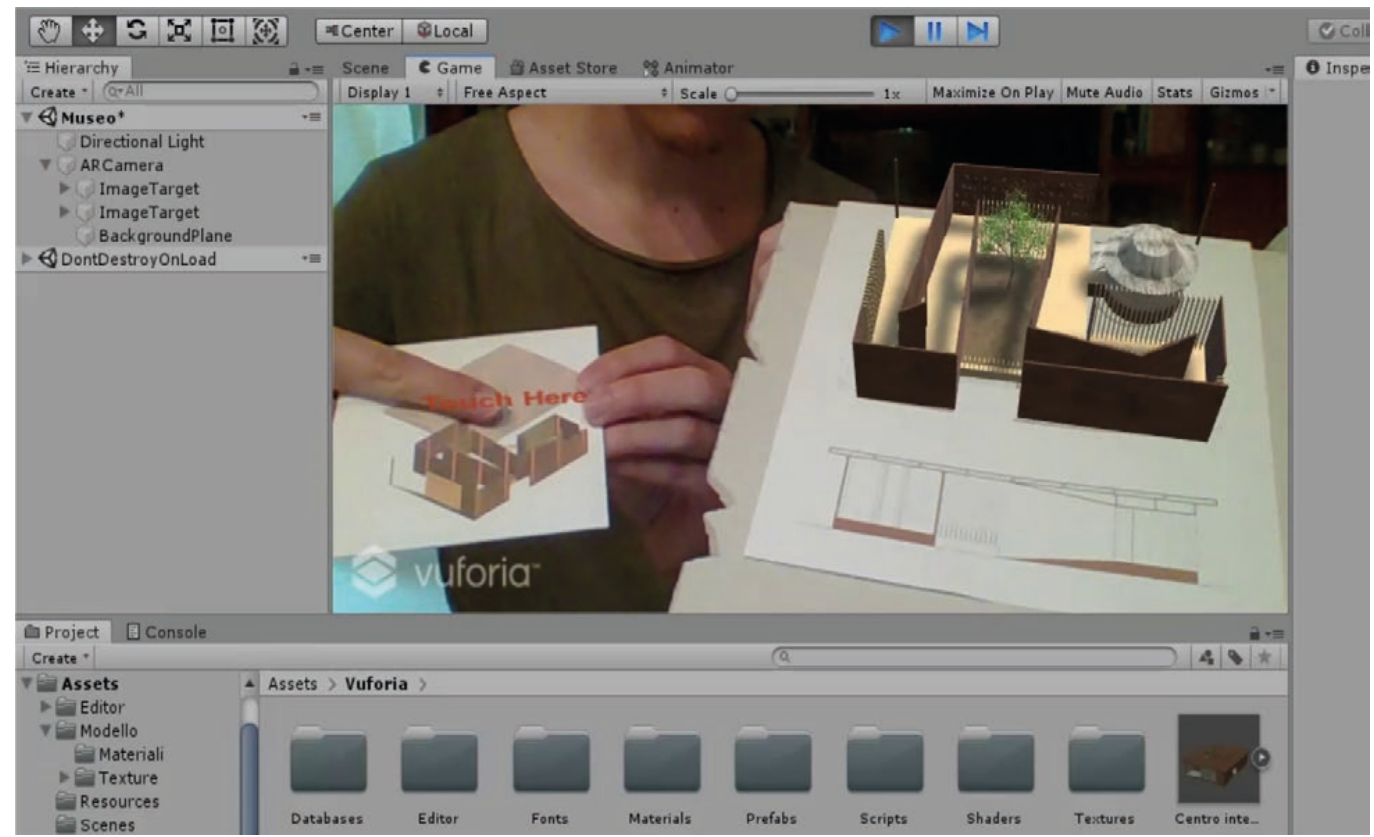




\section{Introduction}

$\mathrm{Al}$ and $\mathrm{AR}$, considered in their significant synergies, have only recently attracted the interest of scholars in the fields of design and enhancement of physical assets. The connection with digital acquisition and modelling technologies makes them ideal media for recognition, communication, and interaction with physical space. In the transdisciplinarity of complex processes that characterize the design activity, the discipline of representation assumes a nodal role. On the one hand, in an increasingly effective way, digital models summarize the prerogatives of drawing and project enclosed in the Latin verb designo and in Alberti's lineamenta. On the other hand, the same models, suitably simplified, become data archives capable of communicating the complexity of reality, increasing the share of transmissible information.

Hence the importance of making these topics part of the research as well as of the teaching in the area of representation, as in the experience we have been conducting since last year in the Digital Representation Techniques class at the School of Architecture at the Politecnico di Torino.
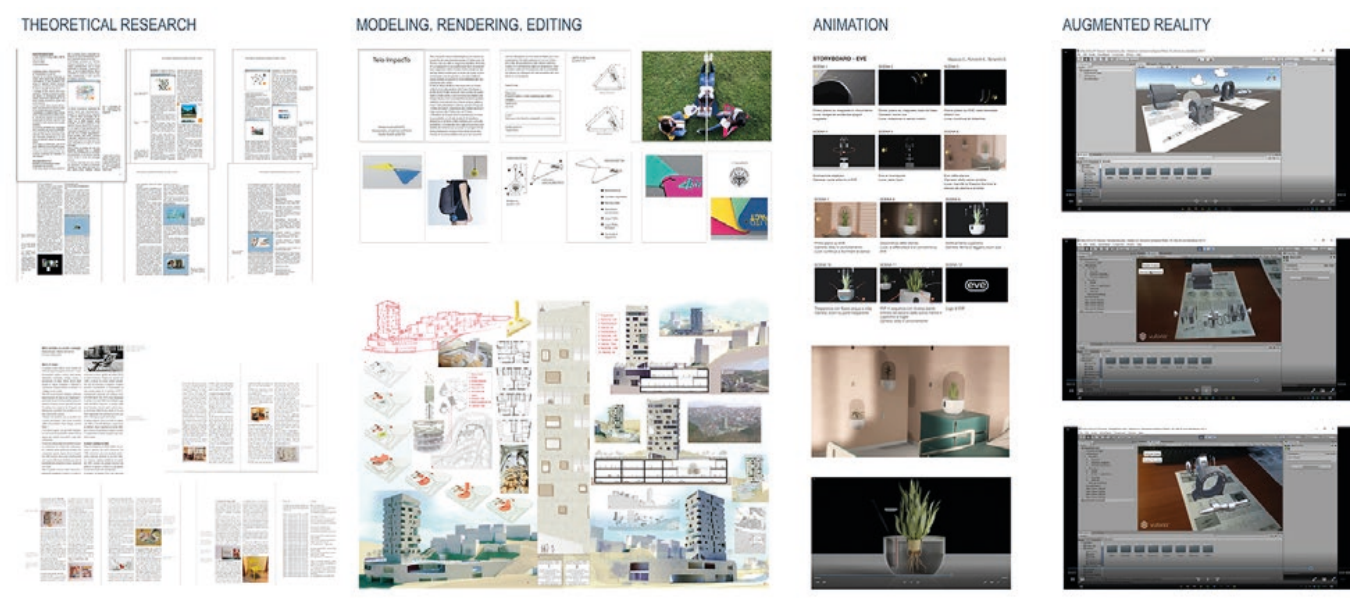

\section{Content and Experimentation of an Evolving Class}

The Digital Representation Techniques class was created in 2006 as an optional class for the Bachelor course in Architectural Sciences. The aim of the class is to provide students with an up-to-date theoretical and applicative overview of the new and evolving trends in digital representation for project development and communication. In view of the interest shown by students, with applications for more than the I 50 places available, in 2013 the course was elected as an optional Athenaeum class, extending the offer to the courses of Design, Territorial Planning and Engineering (this last including around twenty different specializations). The student composition has become increasingly diverse over the years, with engineering students exceeding 35\% in 2021. This has led to new stimuli for us to explore new subject areas, tailoring experiences to the students' curricula.

In the past and current academic year, the class, taught by Roberta Spallone and co-taught by Francesco Carota, Riccardo Covino and Valerio Palma, has aimed at incorporating the inputs offered by the most recent developments in Al and AR technologies. For this reason, Al for computer vision was introduced at a theoretical level through specific lectures held by the teachers and by invited scholars who deepened the relations between computer graphics, computer vision, human-machine interfaces, $\mathrm{Al}$ and also telecommunications and $5 \mathrm{G}$ in support of virtual tourism. AR module has been developed at a theoretical and operational level under the supervision of Valerio Palma.

The theoretical contents of the class focus on the representation and digital communication of the project, and are organized between photography in its relations with rendering, reconstructive modelling, representation in contests, product communication, animation, design communication in websites. The operative contents include learning of rendering and 
animation techniques, developed with Autodesk $\AA 3$ ds Max and Blender software, video editing with DaVinci Resolve, and AR with the combination of the Unity ${ }^{\circledR}$ graphic engine and the Vuforia ${ }^{\circledR}$ Software Development Kit (SDK).

The attention of the teaching team to free and open source software (FOSS) as well as to the possibility of carrying out the proposed experiments with computers and devices commonly in use and at a low cost orient the pedagogical choices.

In addition to an in-depth study of the theory, the practice requires groups of students of different backgrounds to work on the digital model of a project, which scope is defined by their specific skills (i.e. architectural and urban projects, product designs, mechanical components, characters animation, etc).

The operations to be carried out on these models consist of rendering and animation, which flow into static graphic products such as plates or brochures, production of a video and, as will be discussed in more detail below, augmented reality experiences applied to the graphic works (fig. I). The results of this last activity will be presented below, highlighting the interaction between different types of representation and digital communication.

\section{Insight Into the Module of AI\&AR}

The module on Al and AR technologies aims at providing students with skills to deal with new digital tools and the ongoing changes in the use of information in representation and design. The way we structure our knowledge and the way in which the models become operational are deeply influenced by the possibility of producing and collecting an increasing amount of data [Batty 20 16; Datta 20 17]. The tools we bring to the students' attention support the understanding of physical space as a means for accessing information and ordering it. Both Al and AR technologies benefit from the growing computational power available and dedicated hardware and software on mobile devices. Al, which has undergone unprecedented advancements in the last years, has found practical applications related to computer vision in many different fields [Goodfellow et al. 20 I6; Pezzica et al. 2019]. AR applications have spread over the past two decades, and related development tools constantly increase the range of trackable assets and the effectiveness of digital superimposition against real-time images [Amin, Govilkar 20 I 5; Bekele et al. 20 I8]. The physical form of reality is a sort of multidisciplinary platform, a shared grid (tangible and visible) on which to lay many information strata and different interpretations. Thus, the study of Al and AR allows us to reflect on the links between virtual and real, clarify the potential and limits of data, steer the tools towards more flexible, updatable, and scalable solutions.

With this in mind, starting from experiences that mainly concern the architectural and urban scale, we try to stimulate an even wider interest, which may involve the different disciplinary paths of students attending the class. The program section dedicated to AR deals with the current development status of these technologies (both hardware and software), also by

Fig. 2. AR exercises based on image tracking, developed in Unity an Vuforia. On the left: the object is superimposed against its design drawing. On the right: the user can start an animation to see the engine model disassembled; the figure shows the app preview in the Unity development interface. Authors: $M$. Ferraro, M. Marangone, D. Parente (left) E. Burati, A.L. Scardino, M.A Valencia Zeballos (right).
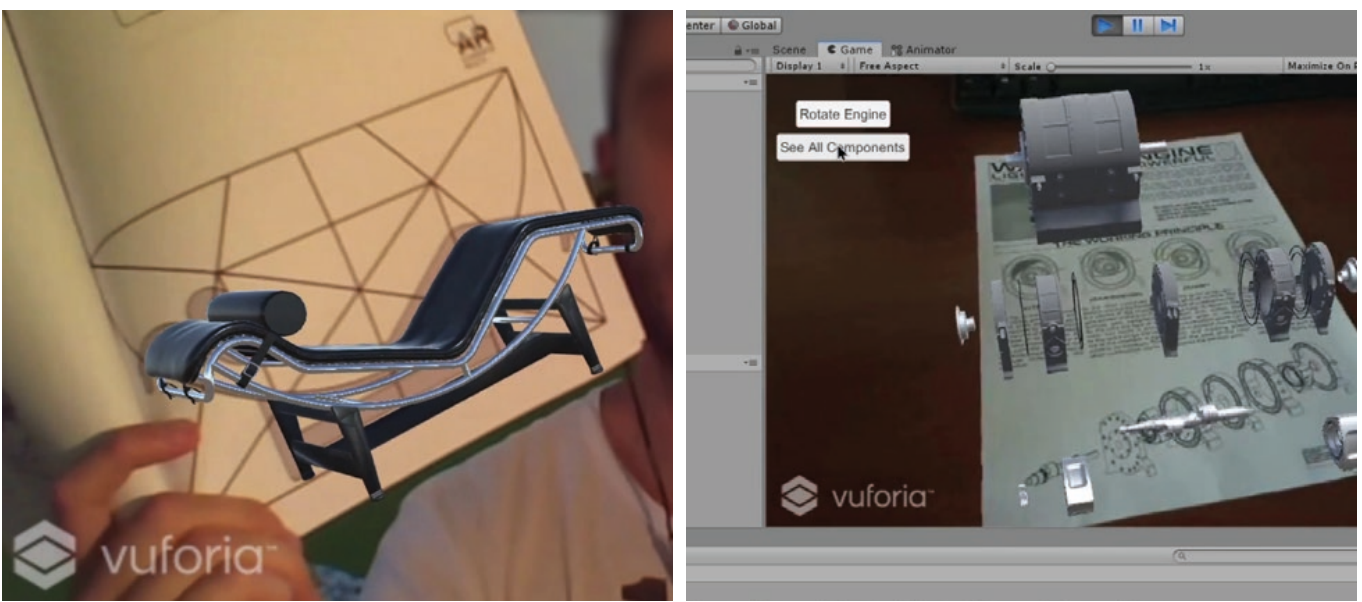
Fig. 3. AR exercise based on image tracking developed in Unity and Vuforia. The target image is printed on a mobile card to simulate an arm prosthesis. When the user reaches the virtual ball, the prosthetic hand grabs it. Authors: G. Brero, A. Porcelli, M. Pettiti.
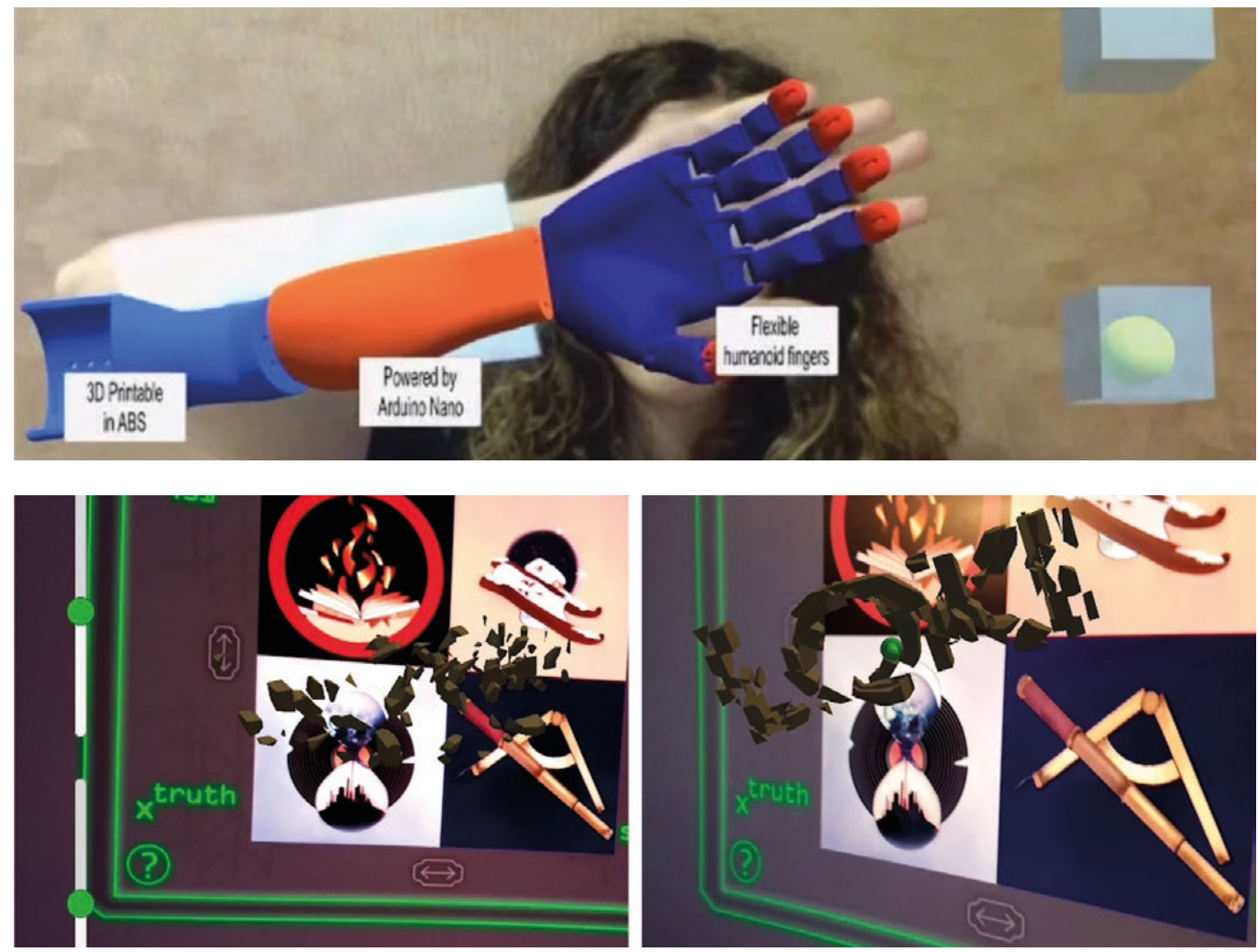

Fig. 4. AR exercise based on image tracking developed in Unity an Vuforia. The students presented a videogame in which the AR target image has to be reassembled before to se the 3D layer. Then, the user is challenged to search the correct hidden message. Authors: Eampolla, V. Mencarelli, D. Fiabane, M. Bosco. presenting the research experiences conducted at the Politecnico by the teachers. Besides, we try to clarify both the potential of the technology and the critical aspects (e.g., limits in interoperability). The theoretical part of the module deals with the most popular $A R, A I$ tools for image recognition (in particular, AR image tracking functions and $D L$ algorithms) and integrates insights into the role of fifth-generation cellular networks (5G) in future scenarios of transmission of information. The aim is to emphasize that technological advances do not only constitute quantitative leaps in data gathering but also require the transformation of the methods and models to organize digital information.

\section{Objectives and Examples of the Students' Work}

In the operational phase of the course (consisting of exercises) we provide the tools for building a simple AR application based on image recognition. We adopt the Unity video game development engine and the Vuforia AR kit, which are software with a short learning curve, requiring little previous experience with coding, and allowing free use for development. However, a broader landscape of competing products and development options is presented. Other practical indications are aimed at stimulating in-depth studies and experiments with particular AR or user interface functions, such as interactive elements, animations, other possibilities related to the integration of scripts and non-flat AR markers. Beyond the technical requirements of the deliverables, students are expected to conduct the exercises reflecting on two fundamental and connected aspects.

I. The first aspect is the link between real space and digital information (such as 3D models, graphic interface elements, databases). We expect students not to consider the real object just as the target for AR activation but as an object that can be studied through its digital model with the help of AR.

2. The second aspect that we ask to explore is the innovativeness of the developed application. In fact, in the case of digital representation, attention must be paid not to replicate uses of the model already available through other widespread technologies, such as virtual reality or simple on-screen navigation. 
Therefore, we aim at continuity with the theoretical part, and we intend to highlight through practice the distinction between the excitement for novelty and more significant and longlasting transformations enabled by technology.

Among the first year's results of this operational phase, several deliverables show good reception of the offered stimuli (the level of complexity depends on the students' choice to deepen AR or other topics in the program).

Some exercises emphasize the relationship between target image and model, letting the two parts complement each other, e.g., by using a printed drawing to show the constructive geometries of a design object while the AR model, correctly scaled, shows the rendering (fig. 2 , left). In other exercises with the simple image target system, students proposed interactive solutions, employing buttons and animations (fig. 2, right).

There are also more elaborate works. A team of computer and biomedical engineering students worked on a robotic prosthetic arm project (started in another class). They produced an application prototype that features a wearable target to simulate the use of the prosthesis. The exercise also included the interaction with other virtual objects, e.g., for activating an animation of the arm (fig. 3). Another team of cinema and media engineering students has instead created a gaming application that features the interaction between a website and the mobile device, proposing an enigma in which AR is used to change the point of view on a three-dimensional object (fig. 4).

\section{Conclusion}

It is difficult to speak of conclusions for a class that is constantly evolving. Rather, by recording the success of the new topics in terms of interest and results, new transdisciplinary perspectives can be outlined, opening up the possibility of developing master's theses and doctoral courses, as is starting to happen. In fact, a thesis in Design and Visual Communication has just been discussed. It combined the disciplines of Representation and Information Processing Systems in the realization of $A R$ and $V R$ experiences for the enhancement of the heritage of the Museum of Oriental Art (MAO) in Turin, and two more on the same topics are being prepared [I].

\section{Notes}

[I] This paper, the result of a teaching activity shared by the two authors, was written by: R. Spallone (Introduction, Content and experimentation of an evolving class, Conclusion) V. Palma (Insight into the module of Al\&AR, Objectives and examples of the students' work).

\section{References}

Amin Dhiraj, Govilkar Sharvari (20 I5). Comparative Study of Augmented Reality SDK's. In International Journal on Computational Science \& Applications, 5( I), pp. I I-26.

Batty, Michael (2016). Editorial: Big Data, Cities and Herodotus. In Built Environment, 42(3), pp. 317-320.

Bekele Mafkereseb Kassahun, Pierdicca, Roberto, Frontoni, Emanuele, Malinverni, Eva Savina, Gain, James (20 I 8). A Survey of Augmented, Virtual, and Mixed Reality for Cultural Heritage. In Journal on Computing and Cultural Heritage, I I (2), pp. I -36.

Datta Shoumen Palit Austin (2017). Emergence of Digital Twins - Is this the march of reason? In Journal of Innovation Management, 5(3), pp. 14-33.

Goodfellow lan, Bengio Yoshua, Courville Aaron (2016). Deep Learning. Cambridge: MIT Press.

Pezzica Camilla, Schroeter Julien, Prizeman Oriel, Jones Christopher, Rosin, Paul (2019). Between Images and Built Form: Automating the Recognition of Standardised Building Components Using Deep Learning. In ISPRS Annals of Photogrammetry, Remote Sensing and Spatial Information Sciences, IV-2 MW, pp. I23-I32.

\footnotetext{
Authors

Roberta Spallone, Dept. of Architecture and Design, Politecnico di Torino, roberta.spallone@polito.it Valerio Palma, Dept. of Architecture and Design, Politecnico di Torino, valerio.palma@polito.it
} 
